\title{
THE IMPACT OF BIOFUELS POLICY AND DROUGHT ON THE U.S. GRAIN AND LIVESTOCK MARKETS
}

\author{
SUNIL P. DHOUBHADEL* \\ Research Analyst, West Central Research \& Extension Center, University of Nebraska-Lincoln, North Platte, Nebraska \\ AZZEDDINE M. AZZAM ${ }^{* *}$ \\ Professor, Department of Agricultural Economics, University of Nebraska-Lincoln, Lincoln, Nebraska \\ MATTHEW C. STOCKTON ${ }^{* * *}$ \\ Assistant Professor, West Central Research \& Extension Center, University of Nebraska-Lincoln, North Platte, \\ Nebraska
}

\begin{abstract}
This article examines the impact of the 2012 drought and the biofuels mandate on the U.S. grain and livestock markets and estimates the mandate waiver required to offset the impact on the corn price. The framework used is a stochastic equilibrium displacement model that integrates the beef, pork, and poultry markets with the corn, distillers' grain, soybean, soymeal, and ethanol markets. The corn and beef markets are found to be the most vulnerable. A mandate waiver of approximately $23 \%$ is required to fully negate the impact of the drought on corn prices. The waiver is equivalent to a $13.7 \%$ reduction in ethanol consumption.
\end{abstract}

Keywords. biofuels mandates, drought, grain and livestock market impact, RIN credits, stochastic EDM

JEL Classifications. Q11, Q13, Q48

\section{Introduction}

The onset of the 2012 drought raised concerns from the livestock sector about the effects of biofuels policies on feed costs, specifically corn and soybean prices. This prompted governors of leading cattle producing states to petition the U.S. Environmental Protection Agency (EPA) to partially waive the Renewable Fuel Standard (RFS) mandate for the 2012/2013 period. The petition was declined by the EPA on the grounds that, based on its own study, the waiver would have "little or no impact on corn, food, and fuel prices" (EPA, 2012, p. 2).

Conclusions from other studies are mixed. Hao et al. (2013) find support for EPA's justification for not waiving the mandate. Irwin and Good (2012)

\footnotetext{
*Email: sdhoubhadel2@unl.edu

**Email: aazzam1@unl.edu

***Email: mstockton2@unl.edu
} 
contend that the cost advantage of blending ethanol in gasoline compared with ethanol substitutes and the technical constraint in ethanol blending (octane wall $^{1}$ ) would take more than a simple waiver to be an effective economic incentive to alter ethanol production significantly. Babcock (2012) and Tyner, Taheripour, and Hurt (2012) present similar arguments; however, they do not completely rule out the possibility of some effectiveness of the waiver in reducing ethanol consumption. Thompson et al. (2012) examine the impacts of the full mandate waiver. Their results are in line with Irwin and Good's (2012) findings in that a mandate waiver would have a minimal effect in reducing ethanol production and hence little impact on corn prices.

Drought is a recurring phenomenon, and if the past is any indication, it is likely that we will continue to have droughts in future. ${ }^{2}$ Additionally, the U.S. government is likely to adjust biofuel mandates based on grain supply and environmental situation. ${ }^{3}$ Given these facts, we use a stochastic equilibrium displacement model (SEDM) to (1) measure the impacts of the RFS mandate on the livestock industry in the presence of a drought-induced crop and pasture shortfall, using the 2012 drought as a case study, and (2) to estimate the degree that the mandate would have to be waived to fully offset the impact of drought on the price of corn. The answers to these questions are crucial in assessing the effectiveness of a mandate waiver.

This article incorporates three features that remain largely unaccounted for in past work. The first is the use of Renewable Fuel Identification Numbers (RINs) and their effect on the markets. RINs are the credits given to blenders by the EPA for each gallon of renewable fuel blended with gasoline. When more gallons of ethanol are blended than is required by the RFS mandate, blenders may carry forward the added production balance as RIN credits to fulfill the following year's mandated production. Because drought years are typically marked by higher corn prices leading to higher ethanol production costs, it is logical to expect that blenders may use RIN credits in place of actual production. Therefore, RIN credits may play a role in mitigating spikes in corn prices during short crop years such as those experienced during drought. Alternatively, lower corn prices due to increased corn supply, such as in 2014, may trigger accumulation of RIN credits due to higher ethanol production and help to decelerate further slide in corn prices due to increased corn demand for ethanol production, assuming ethanol blending economics are favorable.

1 Blend wall and octane wall are discussed later in the article.

2 After the nationwide drought in 2012, California, the largest agricultural producing state in the United States, is facing another severe drought in 2014. A recent report by Bathke et al. (2014) points to the fact that with climate change it is possible that there will be more frequent and severe drought events in the United States. More information about drought and its severity and frequency in the United States can be found at http://www.ncdc.noaa.gov/sotc/drought/\#national-overview.

3 For example, in November 2013 the EPA proposed to reduce corn ethanol mandate for 2014 from 14.4 billion gallons to 13.1 billion gallons. 
The second is the inclusion of cross-price elasticities to capture both the substitution and complementary relationships among the markets for corn grain, distillers' grain (DG), and soybean meal. Livestock are not fed one fixed ration, but rather can be fed differently to obtain the same level of productivity using a variety of formulations to minimize production costs.

The third is the use of confidence intervals and $P$ values of the estimates to test alternative hypotheses about the impacts. The typical literature associated with livestock/ethanol markets (notable examples include Drabik and de Gorter, 2012; Elobeid et al., 2007; Hayes et al., 2009; Kruse et al., 2007; Park and Fortenbery, 2007; Peters et al., 2009; Taheripour, Hertel, and Tyner, 2011; Tokgoz et al., 2008) reports impact results as point estimates without including a statistical distribution around that point. This omission is nontrivial considering that the parameters driving models are themselves stochastic and are derived using statistical means. This work remedies the problem with the point estimate and provides a logically defined method of applying statistical principles to obtain confidence intervals and $P$ values of the estimates to test alternative hypotheses about the impacts.

Additionally, equilibrium displacement models (EDMs) are highly applicable in analyzing policy-induced market equilibrium changes. In these models, the system of demand and supply equations is expressed in terms of proportionate changes in both the endogenous and exogenous variables. For policy analysis, any change is introduced as an exogenous shock in the solution vector of the system of equations, which are then solved simultaneously. The elements of the coefficient matrix of the system of equations are all elasticity estimates or expenditure shares, which are obtained from the literature and/or other reliable sources. The resulting equilibrium displacements represent the proportionate changes in the endogenous variables resulting from the shock or policy changes. ${ }^{4}$

Because EDMs use elasticity estimates from other sources, these models primarily focus on the effect of exogenous shocks to the system and resulting changes in the system equilibria. In contrast to full-fledged multisector econometric models (MSEMs) (e.g., Tokgoz et al., 2008) and error correction models (ECMs) (e.g., Hao, et al., 2013), EDMs do not require times series data, and, hence, they require no econometric estimation. However, because MSEMs account for the microtheoretical restrictions needed to estimate market equilibria and ECMs do not, EDMs are more comparable to MSEMs than ECMs. The latter are concerned with joint dynamic behavior of a set of variables (usually prices) without imposing the microtheoretical restrictions needed to identify the estimated structural parameters linking the prices. What MSEMs and ECMs are able to provide, which EDMs do not, is the dynamic path of the variables as they move from one equilibrium point to another. Therefore, the application of EDMs, MSEMs, or ECMs depends on the objectives of the

4 For an exhaustive review of EDM, see Wohlgenant (2011). 
user, data availability, and the role the modeler prescribes to economic theory in specifying the relationship among variables.

The rest of the article is organized as follows: The "Graphical Presentation of Crop and Livestock Market Equilibrium Displacement Model” section shows a graphical illustration of the EDM used in this article, providing a visual linkage among the eight commodity markets in the model. "The Structural Model" section translates the visual form into a mathematical structural model. "The Equilibrium Displacement Model” section transforms the structural model into a deterministic EDM and presents the method used to make it stochastic, thus laying out the framework for estimating the drought offsetting mandate (DOM) waiver. Finally, results and a summary and conclusion are presented in the last two sections ("Results" and "Summary and Conclusions," respectively).

\section{Graphical Presentation of Crop and Livestock Market Equilibrium Displacement Model}

Before delving into the specifics of the graphical illustration of the model, we first highlight the role of ethanol in the U.S. gasoline market. The RFS mandate, which has been in effect since 2007, requires blenders to mix a fixed proportion of renewable biofuels (ethanol) into gasoline. The gasoline refining industry currently blends an 84 octane gasoline product known as Reformulated Gasoline Blend-stock for Oxygenated Blending (RBOB) with ethanol (113 octane) to produce an 87 octane blended gasoline (Irwin and Good, 2012; Tyner, Taheripour, and Hurt, 2012). Ethanol, therefore, not only helps to fulfill the RFS mandate but also works as an octane enhancer in conventional gasoline. In the United States, typically $10 \%$ of final blended gasoline volume is ethanol. ${ }^{5}$

\subsection{The Market Effects of Drought and the Renewable Fuel Standard Mandate}

Figure 1a depicts the market for gasoline. The intersection of demand and supply schedules for gasoline determines its equilibrium price $\left(P_{G}\right)$ and the quantity $(G)$ of gasoline. The production of $\mathrm{G}$ is defined by a technology where a fixed amount of gasoline is blended with ethanol or a substitute (Figure 1b). The coefficients $\alpha$ and $\beta$ define the minimum requirements of $\mathrm{RBOB}$ and ethanol/substitute blend stock discussed previously. Figure 1d illustrates ethanol production technology from corn grain, and Figure 1e indicates the associated DG production. The amount of ethanol and DG produced per bushel of corn is a fixed quantity. Each bushel of corn produces approximately 2.8 gallons of ethanol (Figure $1 \mathrm{~d}$ ) and 18

5 Higher blends such as E15 (i.e., 15\% ethanol blend gasoline) or E85 (i.e., 85\% ethanol blend), are also available, but compared with E-10, the $10 \%$ ethanol blend, their share in the total blended gasoline market is very small. E-10 blends account for more than $99 \%$ of gasoline blends (EIA, 2012). Similarly, a small proportion of blended gasoline with less than $10 \%$ ethanol blend is also available. 
a) U.S. gasoline market

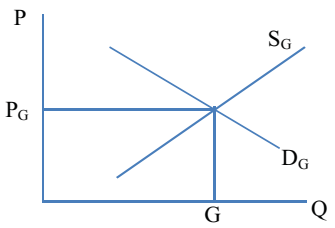

c) Ethanol market

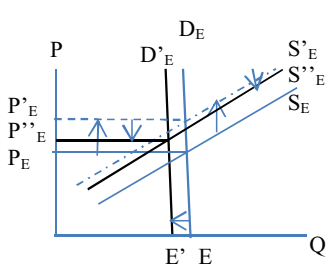

b) Gasoline blending technology

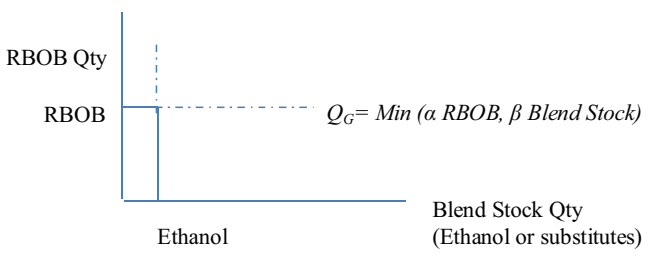

d) Ethanol production technology

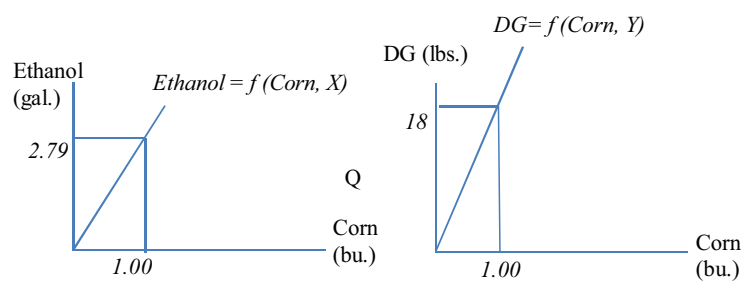

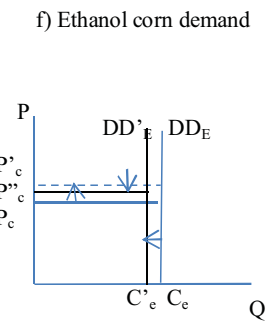

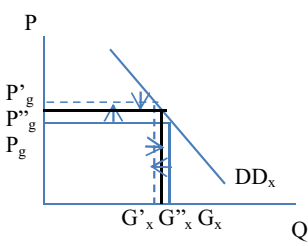

j) DG market

k) Meat market

Without RIN credits
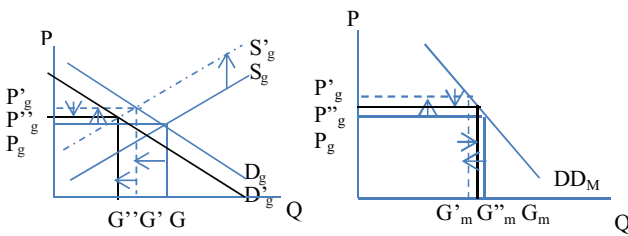

With RIN credits
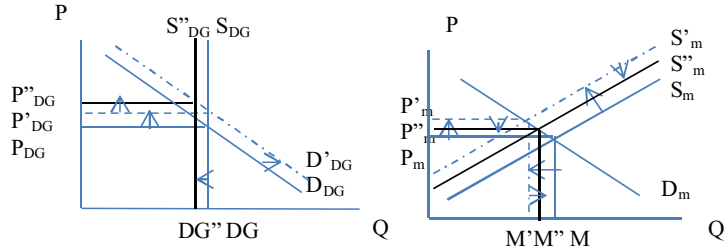

Figure 1. Market Effects of Drought with and without RIN Credits and the RFS Waiver

pounds of DG (Figure 1e), each representing approximately one-third the weight of a bushel of corn.

The source of the ethanol blend stock is the ethanol market represented in Figure 1c. The ethanol supply schedule is upward sloping as usual; however, the ethanol demand curve is relatively inelastic, at least up to a certain quantity of ethanol. The inelastic demand is the result of the RFS mandate and the technical constraints in ethanol blending known as the "blend wall" and the "octane wall" 
(Irwin and Good, 2012; Tyner, Taheripour, and Hurt, 2012). The blend wall exists because blenders cannot blend more than $10 \%$ of the total gasoline volume marketed due to retailing and refining infrastructural constraints. Blending more than $10 \%$ of the total gasoline volume requires adding more pumps, cars, and refineries that can handle a higher level of ethanol, making this an infeasible enterprise in the short run. The octane wall is related to the blending technology. Blending less than $10 \%$ of ethanol with RBOB to enhance the octane level to 87 requires changing the current blending technology, which would require months to achieve. Currently, ethanol is the least expensive source of octane enhancer compared with all other alternatives. Irwin and Good (2012) point out that as long as ethanol is the cheapest alternative and the price of ethanol is below the RBOB price, blenders will continue to prefer ethanol over other alternatives for blending with gasoline. Therefore, due to the blend and octane wall, ethanol demand will continue to be inelastic up to the point where its price is less than or equal to other octane enhancers. However, ethanol is not strictly a domestic product. It can be imported, and, therefore, blenders have some flexibility to substitute imported ethanol from countries such as Brazil, especially if domestic ethanol prices become relatively higher. This fact makes the ethanol demand relatively inelastic as opposed to being perfectly inelastic as shown in Figure 1c. Empirical studies by Elobeid and Tokgoz (2008) and Rask (1998) further support the claim that the demand for ethanol is relatively inelastic.

For illustrative purposes, Figure $1 \mathrm{~h}$ and i represents the derived demands for grains (corn and soybeans) by livestock and exports (later in the EDM, corn and soybeans are treated separately). Figure $1 \mathrm{f}$ represents the derived demand for corn by the ethanol industry. Therefore, the market demand curve for grains, $D_{g}$ (Figure $1 \mathrm{~g}$ ), is the horizontal summation of the derived demands by the ethanol industry, $\mathrm{DD}_{\mathrm{E}}$ (Figure 1f); livestock industries, $\mathrm{DD}_{\mathrm{M}}$ (Figure $1 \mathrm{~h}$ ); and export demand, $\mathrm{DD}_{\mathrm{X}}$ (Figure 1i). The demand for corn grain by the ethanol industry, $\mathrm{DD}_{\mathrm{E}}$ (Figure 1f), is drawn as a vertical line indicating that corn demand for ethanol is perfectly inelastic in the short run. The inelastic corn demand for ethanol reflects the fact that currently corn is the primary viable feedstock used to produce ethanol in the United States, and once ethanol producers decide on the amount of ethanol to be produced, they require a fixed amount of corn grain as shown in Figure 1c and d. The DG market is shown in Figure 1j. The derived demand for DG is captured by the downward sloping schedule, $D_{\mathrm{DG}}$. As a byproduct of ethanol, DG supply is fixed as a proportion of the quantity of corn used to produce ethanol as shown in Figure 1e. Therefore, the supply curve of DG is drawn as a vertical line. The markets for meats are represented by Figure $1 \mathrm{k}$. Again, for illustrative purposes, Figure 1k considers all three meats (beef, pork, and poultry) as one product (meats), and the vertical market structure of the

6 Elobeid and Tokgoz (2008) report an ethanol demand elasticity of -0.43 , and Rask (1998) reports -0.37 . 
meats market is implicit in the figure (later in the algebraic version of the EDM these commodities are treated as separate products and the vertical structure of each meat market is specified).

The market impact of drought without RFS waiver and RIN credits is represented in Figure 1 by arrows that show shifts from the solid demand and supply schedules to their dashed counterparts. The arrows indicate the expected direction of the impact. ${ }^{7}$ The respective supply schedules of the grains market (Figure 1g) shift left, indicating a rise in grains prices (e.g., rise in corn price as shown in Figure 1f) to ethanol producers, livestock producers (Figure 1h), and export price (Figure 1i). The rise in the price of grains (corn) shifts ethanol supply (Figure 1c) and meat supply (Figure 1k) to the left, exacerbating the initial effect of the drought. Demand for DG (a feed substitute for corn in rations) increases, causing a price increase in the DG market (Figure 1j). The effect of drought on the meat marketing chain is transmitted downstream to the feedlot, processing, and retail segments of the chain, resulting in an overall increase in the price of meats.

The effect of RINs and the mandate waiver in the presence of drought is illustrated in Figure 1 by the use of solid dark demand and supply schedules (as opposed to dashed schedules in the case of no RINs and mandate waiver) in the affected markets. Note the potential mitigating effect of the RIN credits and mandate waiver. With the use of RIN credits and the mandate waiver, the price increase is relatively lower in grains (Figure $1 \mathrm{~g}$ ) and meat markets (Figure 1k). Given that the EPA did not grant any mandate waiver in 2012/2013, the solid dark schedules in Figure 1 can be regarded as a result of the use of RIN credits only.

It was projected that at the end of 2012, approximately 1.89 billion gallons of RIN credits will be available to be used for 2013 (Paulson, 2012). ${ }^{8}$ If these RIN credits are used, they shift the blenders' demand curve for ethanol. For example, the 2013 RFS mandate is 13.8 billion gallons of renewable fuel blending. If used fully, the 1.89 billion gallons of RIN credits reduces the demand of ethanol to approximately 12 billion gallons (Figure 1c). Therefore, the RIN credits provide a cushioning mechanism by shifting ethanol demand leftward from $\mathrm{D}_{\mathrm{E}}$ to $\mathrm{D}_{\mathrm{E}}$ (Figure 1c). The leftward shift of ethanol demand translates into a leftward shift in the derived demand of corn from ethanol (from $\mathrm{DD}_{\mathrm{E}}$ to $\mathrm{DD}_{\mathrm{E}}$ in Figure 1f).

\section{The Structural Model}

The structural model consists of several submodels, each corresponding to a specific market. In addition to the meat market, which is segmented into three

7 We say "expected" because of the added effects of cross-price elasticities of the three meats at retail and the cross-elasticities of livestock producers' derived demand of the three feed inputs (corn, DG, and soybean meal).

8 There is a controversy surrounding carryover RIN from 2012. For details, see Paulson (2013). We use Paulson's (2012) estimate as a conservative estimate of carryover RIN from 2012. 
submarkets (i.e., beef, pork, and poultry), the model also includes ethanol and the grain markets consisting of corn, soybeans/soybean meal, and DG. Retail meat demands include both grocery and food away from home, which are the primary generators of demand. Other segments of demands along the supply chain are derived (conditional) demands from adjacent segments downstream. Primary supply is at the farm level and flows to the downstream levels and is derived from upstream levels. The model assumes a fixed proportional relationship between the nonmaterial inputs (labor, packaging, etc.) and the raw material inputs (livestock, feed ingredients, corn, etc.) for both livestock and ethanol. Supplies of nonmaterial inputs are assumed to be perfectly elastic. Substitution is allowed among corn, soybean meal, and DG in meat production at the farm level. Prices and quantities are denoted by $P$ and $Q$, respectively. Only those exogenous shifters such as rainfall and mandate requirement variables are considered. All other shifters are assumed constant and hence suppressed in the model. The specific definitions of the variables in the structural models are listed in Table 1.

\subsection{Meat Markets}

\subsubsection{Beef}

Following RTI International (2007), the beef marketing chain is represented by eight structural equations, which represent four links to submarkets within the supply chain, each defined by its own demand and supply. The four links within the beef supply chain are retail (equations 1-2), processing (equations 3-4), feedlot (equations 5-6), and feeder cattle (equations 7-8). The general forms of the equations are specified as follows: ${ }^{9}$

Retail:

$$
\begin{gathered}
\text { Beef primary demand: } Q_{b}^{r d}=f_{1 b}\left(P_{b}^{r}, P_{p}^{r}, P_{k}^{r}\right) \\
\text { Beef derived supply: } Q_{b}^{r s}=f_{2 b}\left(P_{b}^{r}, Q_{b}^{w}\right)
\end{gathered}
$$

Processing:

$$
\begin{gathered}
\text { Beef derived demand: } Q_{b}^{w d}=f_{3 b}\left(P_{b}^{w}, Q_{b}^{r}\right) \\
\text { Beef derived supply: } Q_{b}^{w s}=f_{4 b}\left(P_{b}^{w}, Q_{b}^{s}\right)
\end{gathered}
$$

9 Note that we use material input quantities rather than material input prices at adjacent levels of the vertical market as arguments in the derived demand and derived supply functions. In the case of derived demands, having downstream material input quantities as arguments rather than material input prices is appropriate (for similar specifications, see Brester, Marsh, and Atwood, 2004; RTI International, 2007). In the case of derived supply, it would be more appropriate to model supply as a function of upstream material-input prices. However, we follow RTI International (2007) and use quantities instead of prices because the RTI study provides estimates of the elasticity of quantity transmission, which we use to empirically implement our model. 
Table 1. Variable Definitions

\begin{tabular}{|c|c|}
\hline Variables & Definitions \\
\hline$Q_{b}^{r}$ & Quantity of beef at the retail level \\
\hline$Q_{b}^{w}$ & Quantity of beef at the processing level \\
\hline$Q_{b}^{s}$ & Quantity of slaughter cattle at the feedlot level \\
\hline$Q_{b}^{f}$ & Quantity of feeder cattle at the farm level \\
\hline$Q_{p}^{r}$ & Quantity of pork at the retail level \\
\hline$Q_{p}^{w}$ & Quantity of pork at the processing level \\
\hline$Q_{p}^{f}$ & Quantity of hog at the farm level \\
\hline$Q_{k}^{r}$ & Quantity of poultry at the retail level \\
\hline$Q_{k}^{w}$ & Quantity of poultry at the processing level \\
\hline$Q_{c o}^{\hat{b}}$ & Quantity of corn for cattle producers \\
\hline$Q_{c o}^{p}$ & Quantity of corn for hog producers \\
\hline$Q_{c o}^{k}$ & Quantity of corn for poultry producers \\
\hline$Q_{c o}^{e}$ & Quantity of corn for ethanol producers \\
\hline$Q_{c o}^{x}$ & Quantity of corn export \\
\hline$Q_{c o}$ & Quantity of total corn \\
\hline$Q_{\text {sym }}^{b}$ & Quantity of soybean meal for cattle producers \\
\hline$Q_{s y m}^{p}$ & Quantity of soybean meal for hog producers \\
\hline$Q_{s y m}^{k}$ & Quantity of soybean meal for poultry producers \\
\hline$Q_{\text {sym }}^{x}$ & Quantity of soybean meal export \\
\hline$Q_{\text {sym }}$ & Quantity of total soybean meal \\
\hline$Q_{s y}^{x}$ & Quantity of soybean export \\
\hline$Q_{s y}^{d}$ & Quantity of domestic soybean \\
\hline$Q_{s y}$ & Quantity of total soybean \\
\hline$Q_{D G}^{b}$ & Quantity of DG for cattle producers \\
\hline$Q_{D G}^{p}$ & Quantity of DG for hog producers \\
\hline$Q_{D G}^{k}$ & Quantity of DG for poultry producers \\
\hline$Q_{D G}^{x}$ & Quantity of DG export \\
\hline$Q_{D G}$ & Quantity of total DG demand \\
\hline$Q_{e}$ & Quantity of ethanol demand \\
\hline$P_{b}^{r}$ & Price of beef at the retail level \\
\hline$P_{b}^{w}$ & Price of beef at the processing level \\
\hline$P_{b}^{s}$ & Price of slaughter cattle at the feedlot level \\
\hline$P_{b}^{f}$ & Price of feeder cattle at the farm level \\
\hline$P_{p}^{r}$ & Price of pork at the retail level \\
\hline$P_{p}^{w}$ & Price of pork at the processing level \\
\hline$P_{p}^{f}$ & Price of hog at the farm level \\
\hline$P_{k}^{r}$ & Price of poultry at the retail level \\
\hline$P_{k}^{w}$ & Price of poultry at the processing level \\
\hline$P_{c o}$ & Price of corn \\
\hline$P_{s y}$ & Price of soybean \\
\hline$P_{\text {sym }}$ & Price of soybean meal \\
\hline$P_{D G}$ & Price of DG \\
\hline$P_{e}$ & Price of ethanol \\
\hline$R$ & Rainfall/drought \\
\hline M & Quantity of ethanol demand changes from mandate or RIN credits \\
\hline$W_{g}$ & Pasture yield \\
\hline
\end{tabular}


Feedlot:

Slaughter fed cattle derived demand: $Q_{b}^{s d}=f_{5 b}\left(P_{b}^{s}, Q_{b}^{w}\right)$

Slaughter fed cattle derived supply: $Q_{b}^{s s}=f_{6 b}\left(P_{b}^{s}, Q_{b}^{f}, P_{c o}, P_{s y m}, P_{D G}\right)^{10}$

Feeder cattle:

$$
\begin{aligned}
& \text { Feeder cattle derived demand: } Q_{b}^{f d}=f_{7 b}\left(P_{b}^{f}, Q_{b}^{s}\right) \\
& \text { Feeder cattle primary supply: } Q_{b}^{f s}=f_{8 b}\left(P_{b}^{f}, W_{g}\right)
\end{aligned}
$$

\subsubsection{Pork}

The structure of the pork marketing chain is similar to that of beef except that it is more vertically integrated with the use of production and marketing contracts (Wise and Trist, 2010). Demand and supply relationships are specified at retail (equations 9-10), processing (equations 11-12), and farm (equations 13-14). Retail:

$$
\begin{gathered}
\text { Pork primary demand: } Q_{p}^{r d}=f_{1 p}\left(P_{p}^{r}, P_{b}^{r}, P_{k}^{r}\right) \\
\text { Pork derived supply: } Q_{p}^{r s}=f_{2 p}\left(P_{p}^{r}, Q_{p}^{w}\right)
\end{gathered}
$$

\section{Processing:}

$$
\begin{gathered}
\text { Pork derived demand: } Q_{p}^{w d}=f_{3 p}\left(P_{p}^{w}, Q_{p}^{r}\right) \\
\text { Pork derived supply: } Q_{p}^{w s}=f_{4 p}\left(P_{p}^{w}, Q_{p}^{f}\right)
\end{gathered}
$$

Farm:

$$
\begin{aligned}
& \text { Derived demand for slaughter hogs: } Q_{p}^{f d}=f_{5 p}\left(P_{p}^{f}, Q_{p}^{w}\right) \\
& \text { Primary supply of slaughter hogs }:^{11} Q_{p}^{f s}=f_{6 p}\left(P_{p}^{f}, P_{c o}, P_{s y m}, P_{D G}\right)
\end{aligned}
$$

10 In the RTI International (2007) model, a meatpacker oligopsony power wedge between the derived demand price, $P_{b}^{s d}$, and the derived supply price, $P_{b}^{s s}$, is captured by the price relationship $P_{b}^{s d}=\rho P_{b}^{s s}$, where $\rho$ is the wedge between the two prices. Assuming drought, $R$, only displaces prices and has no effect on $\rho$ (i.e., $d \rho / d R=0$ ), the displacement in the price relationship can be written as $d P_{b}^{s d}=\rho d P_{b}^{s s}$. Thus, a value of 1 would signify absence of oligopsony power, implying $d P_{b}^{s d}=d P_{b}^{s d}$ and $P_{b}^{s d}=P_{b}^{s s}=P_{b}^{s}$. The values of $\rho$ used in the RTI model range from 1 to 1.038, indicating that the assumption of no oligopsony power that underlines equations (5) and (6) is not unrealistic. Moreover, even if one assumes values slightly larger than 1 for $\rho$, only the magnitude, and not the direction, of the comparative statics results would be affected.

11 The supply function can be derived assuming that revenues of representative hog producers are a weighted average of revenues from the spot market and revenues from production or marketing contracts, where the weights are the proportion of finished hogs sold on the spot market and the proportion of finished hogs sold through contracts. For simplicity of the model, we do not segment the markets here. 


\subsubsection{Poultry}

The poultry supply chain is fully integrated from processing to the farm level (Weng, 2012). We, therefore, consider only retail (equations 15-16) and processing (equations 17-18) demand and supply.

Retail:

$$
\begin{gathered}
\text { Poultry primary demand: } Q_{k}^{r d}=f_{1 k}\left(P_{k}^{r}, P_{b}^{r}, P_{p}^{r}\right) \\
\text { Poultry derived supply: } Q_{k}^{r s}=f_{2 k}\left(P_{k}^{r}, Q_{k}^{w}\right)
\end{gathered}
$$

Processing:

$$
\begin{aligned}
& \text { Poultry derived demand: } Q_{k}^{w d}=f_{3 k}\left(P_{k}^{w}, Q_{k}^{r}\right) \\
& \text { Poultry primary supply: } Q_{k}^{w s}=f_{4 k}\left(P_{k}^{w}, P_{c o}, P_{s y m}, P_{D G}\right)
\end{aligned}
$$

\subsection{Grain Markets}

\subsubsection{Corn}

The structural model of the corn marketing chain consists of derived demands for corn by cattle, hog, poultry, and ethanol producers and corn export demand (equations 19-23). The horizontal sum of the demands is given by equation (24). Corn supply is captured by equation (25).

Derived demand of corn from cattle: $Q_{c o}^{b}=f_{1 c o}\left(P_{c o}, Q_{b}^{s}, P_{s y m}, P_{D G}\right)$

Derived demand of corn from hog: $Q_{c o}^{p}=f_{2 c o}\left(P_{c o}, Q_{p}^{f}, P_{s y m}, P_{D G}\right)$

Derived demand of corn from poultry: $Q_{c o}^{k}=f_{3 c o}\left(P_{c o}, Q_{k}^{w}, P_{s y m}, P_{D G}\right)$

Derived demand of corn from ethanol: $Q_{c o}^{e}=f_{4 c o}\left(P_{c o}, Q_{e}\right)$

Corn export demand: $Q_{c o}^{x}=f_{5 c o}\left(P_{c o}\right)$

Total corn demand: $Q_{c o}^{d}=Q_{c o}^{b}+Q_{c o}^{p}+Q_{c o}^{k}+Q_{c o}^{e}+Q_{c o}^{x}$

Corn supply: $Q_{c o}^{s}=f_{6 c o}\left(P_{c o}, R\right)$

\subsubsection{Soybean and Soybean Meal ${ }^{12}$}

The soybean meal marketing chain has total demand (equation 30), which is the sum of derived demands by cattle (equation 26), hog (equation 27), and poultry producers (equation 28), and soybean meal export demand (equation 29). Soybean meal supply is represented in equation (31). Domestic and export

12 Soybean meal and soybean oil are the joint products produced by using soybean as the main input for production. Therefore, the supply of these joint products is highly dependent on supply of soybean. 
demands for soybean are represented in equations (32) and (33). Total demand and supply of soybeans is represented in equations (34) and (35), respectively. Soybean meal:

Derived demand of soybean meal from cattle:

$$
Q_{\text {sym }}^{b}=f_{1 s y m}\left(P_{c o}, Q_{b}^{s}, P_{s y m}, P_{D G}\right)
$$

Derived demand of soybean meal from hog:

$$
Q_{\text {sym }}^{p}=f_{2 s y m}\left(P_{c o}, Q_{p}^{f}, P_{s y m}, P_{D G}\right)
$$

Derived demand of soybean meal from poultry:

$$
Q_{\text {sym }}^{k}=f_{3 s y m}\left(P_{c o}, Q_{k}^{w}, P_{s y m}, P_{D G}\right)
$$

Soybean meal export demand: $Q_{s y m}^{x}=f_{4 s y m}\left(P_{\text {sym }}\right)$

Total soybean meal demand: $Q_{s y m}^{d}=Q_{s y m}^{b}+Q_{s y m}^{p}+Q_{s y m}^{k}+Q_{s y m}^{x}$

Soybean meal supply: $Q_{\text {sym }}^{s}=f_{5 s y m}\left(P_{s y m}, Q_{s y}\right)$

Soybeans:

$$
\begin{aligned}
\text { Soybean domestic demand: } Q_{s y}^{d} & =f_{1 s y}\left(P_{s y}, P_{s y m}\right) \\
\text { Soybean export demand: } Q_{s y}^{x} & =f_{2 s y}\left(P_{s y}\right) \\
\text { Total soybean demand: } Q_{s y} & =Q_{s y}^{d}+Q_{s y}^{x} \\
\text { Soybean supply: } Q_{s y} & =f_{3 s y}\left(P_{s y}, R\right)
\end{aligned}
$$

\subsection{Distillers' Grain Market}

The derived demand for DG (equation 40) is the sum of the derived demands for DG from cattle (equation 36), pork (equation 37), poultry (equation 38), and exports (equation 39). Primary supply of DG (equation 41) is specified as a fixed proportion of corn used for ethanol production.

Derived demand of DG from cattle: $Q_{D G}^{b}=f_{1 D G}\left(P_{c o}, Q_{b}^{s}, P_{s y m}, P_{D G}\right)$

Derived demand of DG from hog: $Q_{D G}^{p}=f_{2 D G}\left(P_{c o}, Q_{p}^{f}, P_{s y m}, P_{D G}\right)$ (37)

Derived demand of DG from poultry: $Q_{D G}^{k}=f_{3 D G}\left(P_{c o}, Q_{k}^{w}, P_{s y m}, P_{D G}\right)$ (38)

DG export demand: $Q_{D G}^{x}=f_{3 D G}\left(P_{D G}\right)$

Total DG demand: $Q_{D G}^{d}=Q_{D G}^{b}+Q_{D G}^{h}+Q_{D G}^{k}+Q_{D G}^{x}$

DG supply: $Q_{D G}^{s}=0.18 Q_{c o}^{e}$ 


\subsection{Ethanol Market}

Ethanol demand by gasoline blenders is represented by equation (42). The primary supply of ethanol by producers is captured in equation (43).

Derived demand of ethanol from the blenders: $Q_{e}^{d}=f_{1 e}\left(P_{e}, M\right)$

$$
\text { Ethanol supply: } Q_{e}^{s}=f_{2 e}\left(P_{e}, P_{c o}\right)
$$

\section{The Equilibrium Displacement Model}

Total differentiation of the structural model (equations 1 through 43) and their expression in $\log$ differential form provides a system of $43 \mathrm{log}$ differential equations (Appendix). The log differential form of each of the 43 equations represents percent changes, with the endogenous (exogenous) variables on the left-hand (right-hand) side of the equality sign. With the exception of the three exogenous shocks of interest- $d \ln R$ (in equations A-25 and A-35), representing the proportionate change in rainfall/drought; $d \ln W_{g}$ (in equation A-8), the proportionate change in pasture yield; and $d \ln M$ (in equation A-42), the proportionate change in ethanol blended due to the RFS mandate waiver and/or use of RIN credits-the log differentials of the remaining exogenous variables are set equal to zero.

Denoting the vector of percentage changes in the endogenous variables

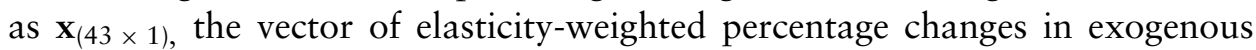
variables as $\mathbf{b}_{(43 \times 1)}$, and the coefficient matrix by $\mathbf{A}_{(43 \times 43)}$, the system is represented in a matrix form as

$$
\mathbf{A}_{(43 \times 43)} \cdot \mathbf{x}_{(43 \times 1)}=\mathbf{b}_{(43 \times 1)},
$$

and the solution of the system as

$$
\mathrm{X}_{(43 \times 1)}=\mathrm{A}^{-1} \mathbf{b} \text {. }
$$

The elements of the coefficient matrix A represent either elasticity estimates or quantity shares. Most of these estimates are obtained from literature, and others estimated by the authors. ${ }^{13}$ The sources of the elasticities used to weight the percentage changes in the exogenous variables of interest $\left(d \ln R, d \ln W_{g}\right.$, and $d \ln M)$ are provided in the Appendix.

\subsection{The Stochastic Model}

Davis and Espinoza (1998) highlight the usefulness of a stochastic framework compared with using single point deterministic estimates or a simple sensitivity analysis with a limited number of adjustments. They contend that the deterministic framework does not provide a way for determining the statistical

13 For space consideration, these elasticity estimates and their sources are not reported here. They are available as an online supplementary appendix. 
merit of the estimated percentage changes in the endogenous variables. Conversely, the stochastic framework provides a distribution of points around an estimate, which provides such a framework. They also indicate that unlike a typical sensitivity analysis in which point estimates are selected at the discretion of the researcher, the stochastic framework estimates are randomly drawn from a distribution avoiding biases introduced by the researcher. Our analysis adopts the Davis and Espinoza (1998) framework, which we consider an SEDM instead of a standard deterministic EDM for analysis. Although Davis and Espinoza (1998) show the superiority of using the SEDM method, they provide little guidance for selecting the proper distribution to be simulated. One of the contributions of this article is that simple basic statistical principles are used to develop a method of constructing the unknown distributions of the estimates.

The elasticity estimates comprising the coefficient matrix A are gathered from the literature. As econometric estimates represent a single realization in a distribution of estimates, the parent distribution from which they are taken may theoretically be used to draw additional estimates. Unfortunately, many of the elasticity estimates obtained from literature do not report information about these parent distributions. Moreover, multiple estimates of a single elasticity are available from various sources that use varying estimation methods, which may or may not have compatible assumptions about their individual distributions. Therefore, a choice about what is a reasonable method for selecting appropriate sensitivity values is made. What is known is that multiple elasticities collected from various sources are available and could themselves be considered a sample of observations (i.e., elasticity estimates). Given this, the central limit theorem suggests that the sampling distribution of the sample mean approaches a normal distribution (Casella and Berger, 2002). In practice, a normal distribution is approximated by the $t$ distribution for small samples such as the sample of elasticity estimates obtained from literature, which are many times four or less implying small degrees of freedom (df). The calculated value for a $t$ statistic is the relevant elasticity value divided by its standard deviation. In this work, $t$ value is obtained from the $t$ table for $\mathrm{df}=3$ and a one-tailed level of significance of 0.005 , which is calculated as 5.841. Then, using this $t$ value and the elasticity estimates from literature, standard deviation $(\sigma)$ of the elasticity estimates is extrapolated. The estimated $\sigma$ is then used to stochastically simulate the distribution of elasticity estimates around the true mean of the estimates. Purposely, a large confidence level (i.e., a level of significance of 0.005 ) is used to reflect a high degree of confidence in the elasticity estimates from the literature. Consequently, the lower the confidence level, the larger is the $\sigma$ value. Larger $\sigma$ values allow for wider variation in the stochastically drawn elasticities. The idea is to have parsimony, enough variation to test sensitivity but not so much that stochastically drawn elasticities are far away from those reported in the literature. Given that the estimates were estimated properly (i.e., no violation of any of the modeling 
assumptions), this method provides a statistically relevant method of establishing ranges for the sensitivity parameters.

Now that we have the $\sigma$ values of the estimates, the next step is to select a type of distribution for simulating the estimates. Although the central limit theorem suggests that the sampling distribution of the elasticity estimates is likely to be normally distributed, we do not know the true mean of this distribution. This implies that any of the elasticity estimates from the literature can equal the true mean. Given the fact that we do not know the true mean, we assign equal probability of selection to each of the alternative elasticity estimates when they are simulated; that is, a uniform distribution is used. The uniform distribution assures that each observation of elasticity within a specified range is equally likely as the true mean and is used in the simulation process. A single standard deviation of the estimates is used as upper and lower limits of the uniform distribution, making it a conservative simulation. Moreover, the demand elasticities are restricted to be negative and supply elasticities to be positive.

We assume independence among the elasticity estimates, which at first may seem unreasonable. Again, consider the estimates and the process that created them. Presumably, the estimates were created in a model that has little or no misspecification error, indicating that the estimates themselves have been purged of any interdependencies among the variables in the model. This assumption allows each elasticity estimate to be randomly drawn without considering its effect on any other elasticity. If this were not the case, a variance covariance matrix would be required. Because the estimates are collected from a wide variety of sources, information needed to create the variance covariance structure is neither available nor feasible. In such a circumstance, guessing at the variance covariance structure and incorporating it into the model would add additional bias (Davis and Espinoza, 1998).

To summarize, the $t$ distribution defines the area with a specific degree of confidence where the true mean is likely to lie, and the uniform distribution provides a pool of equally likely candidates of true means. The process of generating elasticity estimates using this process fulfills four objectives: (1) it makes them stochastic within a very close neighborhood of the original estimates from literature, (2) it uses a random selection based on central tendency, (3) it provides a method to determine statistical significance, and (4) it addresses the concerns expressed by Davis and Espinoza (1998).

The resulting posterior distributions of the endogenous variables are simulated 1,000 times using the Microsoft Excel add-on simulation software SIMETAR 2011 (Richardson, Schumann, and Feldman, 2008). The Latin Hypercube simulation procedure is the one applied in SIMETAR. Based on the simulation, using Chebychev inequality a $90 \%$ confidence interval is constructed around the simulated means of the endogenous variables, and their associated maximum $P$ values are calculated (Davis and Espinoza, 1998). Construction of the 
confidence intervals and associated maximum $P$ values provides information on the statistical significance of the simulated mean values making it possible to determine at what level the final results of the model becomes statistically significant.

\subsection{Drought Offsetting Mandate Waiver}

By DOM waiver we mean the reduction in the RFS mandate necessary to offset the effects of drought such that the price of corn would remain unchanged. To do this, we start with the reduced form of the equilibrium price of corn, $P_{c o}$, and set it as a function of the mandate and drought variables:

$$
P_{c o}=f(M, R),
$$

where $M$ (the mandate) and $R$ (rainfall/drought) are exogenous variables whose proportional changes drive the equilibrium displacement of all the other endogenous variables. Total differentiation of equation (46) yields equation (47):

$$
d \ln P_{c o}=\varepsilon_{P_{c o, M}} d \ln M+\varepsilon_{P_{c o, R}} d \ln R,
$$

where $\varepsilon_{P_{c o, R}}=\left(\frac{d P}{d R}\right)\left(\frac{R}{P}\right)$ is the corn price elasticity with respect to a change in rainfall, and $\varepsilon_{P_{c o, M}}=\left(\frac{d P}{d M}\right)\left(\frac{M}{P}\right)$ is the corn price elasticity with respect to a change in the mandate. Then, by setting $d \ln P_{c o}=0$ and solving for the DOM, the result is equation (48):

$$
\frac{d \ln M}{d \ln R}=-\frac{\varepsilon_{P_{c o, R}}}{\varepsilon_{P_{c o, M}}} \text { for } d \ln P_{c o}=0
$$

The equation gives the percent change in the ethanol mandate required to offset the effect on corn price of a $1 \%$ change in rainfall. To compute equation (48), the elasticity in the numerator (denominator) is obtained by solving the EDM for the equilibrium price of corn assuming a $1 \%$ change in rainfall, $R$ (mandate, $M)$, and no change in mandate, $M$ (rainfall, $R$ ).

\section{Results}

Using the 11-year average rainfall (average of cumulative rainfall between April and August) data published by the National Climatic Data Center for the Corn Belt area as the baseline, the proportion of deficit rainfall in 2012 compared with the baseline average was estimated. The rainfall in the Corn Belt area during 2012 was approximately $32 \%$ less than the baseline. The percentage decrease 
in rainfall is weighted by its elasticity values and then used as the shock to the exogenous variable $R .{ }^{14}$

The multimarket impacts of a $32 \%$ drop in rainfall are analyzed in conjunction with the effect of the RFS mandate. Because the EPA did not waive the RFS mandate target for 2012, the only flexibility ethanol blenders have in blending ethanol is the use of RIN credits. However, note that the exogenous variable $M$ represents both RFS mandate waivers and RIN credit use by blenders, and either/both potentially shift ethanol demand. In this case, $M$ represents RIN credits only. As we mentioned previously, Paulson (2012) reported that approximately 1.89 billion gallons of RIN credits were available to be used toward fulfilling the RFS mandate deficit at the end of 2012. These credits could have fulfilled approximately $13.9 \%$ of the 13.6 billion gallons required by RFS mandate for 2012/2013 period, allowing blenders to use less ethanol without violating the mandate if they chose to.

In our analysis, two scenarios are considered: drought impacts with and without the use of all the available RIN credits.

\subsection{Scenario 1: Multimarket Impact of Drought without the Use of RIN Credits}

Table 2 shows the impact on the meat sector. In general, the magnitude of the impact on equilibrium prices and quantities is higher for beef than pork and poultry. A $32 \%$ drop in rainfall leads to $4.9 \%[1.3,8.4],{ }^{15} 1.1 \%[0.4$, $1.8]$, and $2.1 \%[0.8,3.5]$ increase in the retail prices of beef, pork, and poultry, respectively. Although retail prices for all meats show an increase, their respective retail quantities do not-beef consumption drops by $3.1 \%[-5.4,-0.7]$, but pork and poultry consumption remain unchanged. The larger impact of drought on beef is driven by two factors: (1) drought affects the availability of pasture for cattle, and (2) drought impacts the production of corn and soybean, which are the major sources of feed in finished beef production. Unlike beef production, pork and poultry are affected only through the impact on feed production.

Along the meat marketing chain, the largest price impact is observed at the processor level in the beef and pork marketing chain where price increases by $6.3 \%[1.9,10.8]$ and $1.2 \%[0.4,1.9]$, respectively. In terms of output impact, the largest drop in quantity is at the farm level with $10.4 \%[-11.6,-9.3]$ and $0.5 \%[-0.9,-0.1]$ decline for beef and pork, respectively. In the case of poultry, the largest price impact is observed at the retail level, and there are no significant quantity changes at all levels. These results indicate a differential impact of drought on all three meat marketing chains. The differential impact along the

14 The shock to exogenous variable $R$ is weighted by crop yield elasticity of rainfall as provided in footnotes 21 and 22. By using crop yield elasticity of rainfall as weights in the rainfall shocks, the model takes into account the effects of changes in crop yield due to drought.

15 Values in the brackets are the $90 \%$ confidence intervals. 
Table 2. Meat Market Impact of $32 \%$ Decrease in Rainfall a

\begin{tabular}{|c|c|c|c|c|c|c|c|c|c|c|c|}
\hline \multirow[b]{3}{*}{ Markets } & \multirow[b]{3}{*}{$\begin{array}{l}\text { Proportionate } \\
\text { Change }\end{array}$} & \multicolumn{5}{|c|}{ Without the Use of RIN Credits } & \multicolumn{5}{|c|}{ With the Use of RIN Credits } \\
\hline & & \multirow[b]{2}{*}{$\begin{array}{l}\text { Mean } \\
1\end{array}$} & \multirow{2}{*}{$\begin{array}{l}\text { Standard } \\
\text { Deviation } \\
2\end{array}$} & \multicolumn{2}{|c|}{$\begin{array}{l}90 \% \text { Confidence } \\
\text { Interval }\end{array}$} & \multirow{2}{*}{$\begin{array}{l}\text { Max } P \\
\text { Value } \\
5\end{array}$} & \multirow[b]{2}{*}{$\begin{array}{l}\text { Mean } \\
6\end{array}$} & \multirow{2}{*}{$\begin{array}{l}\text { Standard } \\
\text { Deviation } \\
7\end{array}$} & \multicolumn{2}{|c|}{$\begin{array}{l}90 \% \text { Confidence } \\
\text { Interval }\end{array}$} & \multirow{2}{*}{$\begin{array}{l}\text { Max } P \\
\text { Value } \\
10\end{array}$} \\
\hline & & & & $\begin{array}{l}\text { Lower } \\
3\end{array}$ & $\begin{array}{l}\text { Upper } \\
4\end{array}$ & & & & $\begin{array}{l}\text { Lower } \\
8\end{array}$ & $\begin{array}{l}\text { Upper } \\
9\end{array}$ & \\
\hline \multirow[t]{8}{*}{ Beef } & Retail price & 0.049 & 0.011 & 0.013 & 0.084 & 0.053 & 0.047 & 0.011 & 0.012 & 0.082 & 0.054 \\
\hline & Retail quantity & -0.031 & 0.007 & -0.054 & -0.007 & 0.059 & -0.030 & 0.007 & -0.054 & -0.007 & 0.059 \\
\hline & Processor price & 0.063 & 0.014 & 0.019 & 0.108 & 0.050 & 0.062 & 0.014 & 0.018 & 0.107 & 0.050 \\
\hline & Processor quantity & -0.068 & 0.013 & -0.109 & -0.026 & 0.038 & -0.067 & 0.013 & -0.108 & -0.025 & 0.038 \\
\hline & Slaughter price & 0.034 & 0.015 & -0.015 & 0.082 & 0.207 & 0.033 & 0.015 & -0.015 & 0.081 & 0.209 \\
\hline & Slaughter quantity & -0.091 & 0.012 & -0.130 & -0.053 & 0.017 & -0.090 & 0.012 & -0.128 & -0.052 & 0.018 \\
\hline & Farm price & 0.053 & 0.016 & 0.002 & 0.105 & 0.092 & 0.055 & 0.016 & 0.004 & 0.105 & 0.087 \\
\hline & Farm quantity & -0.104 & 0.004 & -0.116 & -0.093 & 0.001 & -0.104 & 0.004 & -0.116 & -0.092 & 0.001 \\
\hline \multirow[t]{6}{*}{ Pork } & Retail price & 0.011 & 0.002 & 0.004 & 0.018 & 0.040 & 0.009 & 0.002 & 0.002 & 0.016 & 0.055 \\
\hline & Retail quantity & 0.008 & 0.003 & -0.001 & 0.018 & 0.133 & 0.009 & 0.003 & 0.000 & 0.019 & 0.093 \\
\hline & Processor price & 0.012 & 0.002 & 0.004 & 0.019 & 0.039 & 0.009 & 0.002 & 0.002 & 0.016 & 0.058 \\
\hline & Processor quantity & 0.000 & 0.002 & -0.006 & 0.007 & 1.000 & 0.003 & 0.002 & -0.003 & 0.009 & 0.356 \\
\hline & Farm price & 0.011 & 0.002 & 0.003 & 0.018 & 0.051 & 0.008 & 0.002 & 0.001 & 0.015 & 0.073 \\
\hline & Farm quantity & -0.005 & 0.001 & -0.009 & -0.001 & 0.065 & -0.001 & 0.001 & -0.004 & 0.002 & 1.000 \\
\hline \multirow[t]{4}{*}{ Poultry } & Retail price & 0.021 & 0.004 & 0.008 & 0.035 & 0.039 & 0.019 & 0.004 & 0.006 & 0.032 & 0.048 \\
\hline & Retail quantity & 0.003 & 0.001 & -0.001 & 0.007 & 0.166 & 0.003 & 0.001 & 0.000 & 0.007 & 0.117 \\
\hline & Processor price & 0.017 & 0.004 & 0.006 & 0.029 & 0.047 & 0.015 & 0.004 & 0.003 & 0.027 & 0.059 \\
\hline & Processor quantity & -0.001 & 0.001 & -0.003 & 0.001 & 0.551 & 0.000 & 0.001 & -0.002 & 0.002 & 1.000 \\
\hline
\end{tabular}

Note: The values in Table 2 and subsequent tables are in terms of proportionate change, which needs to be multiplied by 100 to get the percentage change. 
marketing chain is largely driven by the own- and cross-elasticities of demand at retail, and substitution among the feed grains at the farm level.

Results in Table 3 show that without the use of RIN credits, drought has the largest impact on corn with $8.8 \%[7.1,10.6]$ increase in price and a $2.9 \%$ $[-3.4,-2.4]$ decline in quantity. The impact is smaller in the case of soybean and soybean meal with $5.1 \%[3.6,6.6]$ and $7.4 \%[5.9,9.0]$ increase in the price and a $1.9 \%[-2.2,-1.6]$ and $5.5 \%[-6.0,-4.9]$ decline in quantity, respectively. For DG, there is no significant change in price and quantity. Note that grain and feed markets are the ones directly affected by drought; the magnitude of impact on these markets is generally higher compared with meat markets. The drought impacts are lessened as one moves through the production chain from grain and feed to meat. The higher corn prices due to drought induce a $1.8 \%[0.9,2.7]$ increase in the ethanol price, and there is no decline in ethanol consumption as no RIN credits are used.

Drought without the use of RIN credits decreases corn export demand by $9.8 \%[-12.1,-7.4]$ and corn demand for cattle feed by $8.9 \%[-12.3,-5.4]$. There is no significant reduction in pork and poultry corn demand for feed. For soybeans, both domestic and export demand are reduced by $10.4 \%[-12.2$, $-8.7]$ and $1.5 \%[-2.4,-0.5]$, respectively. The reduction in domestic soybean demand is driven by a $9.6 \%[-13.5,-5.7]$ and $4.6 \%[-5.9,-3.2]$ decline in soybean meal demand from the cattle feeding sector and export demand, respectively. Unlike soybean meal, for which demand from pork and poultry remains unchanged, DG demand from these sectors increases by $5.3 \%[3.3,7.3]$ and $5.6 \%[3.6,7.6]$. However, the demand for DG by cattle feeding operations decreases by $3.1 \%[-5.8,-0.5]$, whereas export demand remains unchanged. These results are consistent with static equilibrium quantities of pork and poultry at the upstream (processing) levels, leaving feed demand by the two sectors unaffected. The reduced feed demand from the cattle sector is to be expected considering the impacts of drought on calf production leads to some cow/calf liquidation. All of the previously discussed results emphasize the dual impact of drought on beef through both pasture and feed grains, whereas pork and poultry are relatively spared. ${ }^{16}$

\subsection{Scenario 2: Multimarket Impact of Drought with the Use of RIN Credits}

There is a little difference in the impact of drought with and without the use of RIN credits at almost all levels of the meat marketing chain (Table 2). Whenever

16 Although our results are not directly comparable with the results reported by Hao et al. (2013), because they use a time series model framework and we use an EDM, it is worth noting that they find corn prices to be the least sensitive to drought, whereas we find corn prices are the most affected by drought. Also, unlike Hao et al. (2013), our results indicate a relatively small but significant impact of drought on pork, poultry, and ethanol markets. However, their conclusion that in general crops and beef markets are the most affected by the drought compared with pork, poultry, ethanol markets is line with the results from this analysis. 
Table 3. Grain, Feed, and Ethanol Market Impact of 32\% Decrease in Rainfall

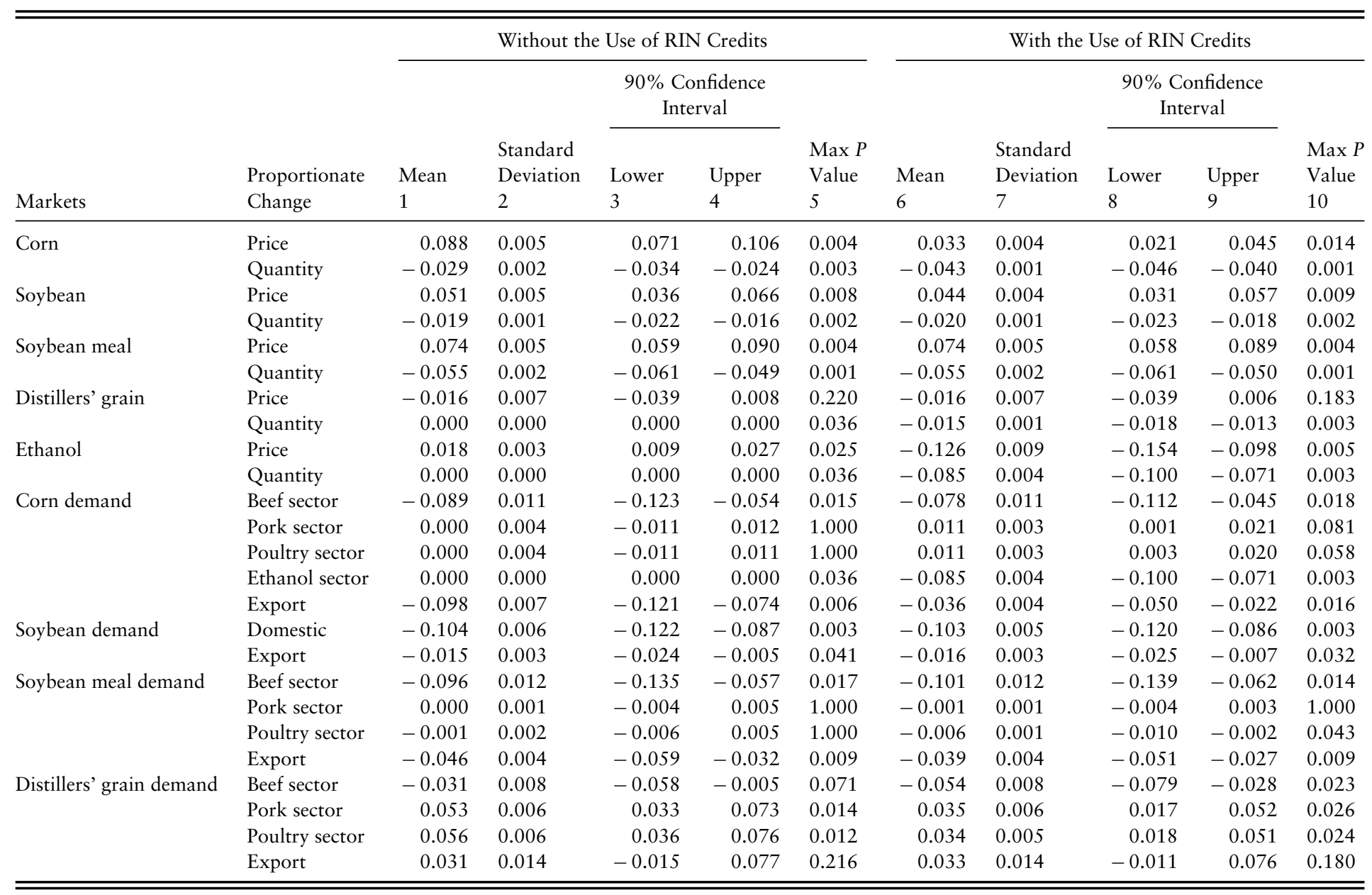


Table 4. Level of Mandate Waiver Required to Fully Offset the Impact on the Equilibrium Corn Price of the $32 \%$ Decrease in Rainfall

\begin{tabular}{llllll}
\hline \hline & & & \multicolumn{2}{c}{$90 \%$ Confidence } \\
Interval & \\
\cline { 4 - 5 } Proportionate & Stochastic & Standard & & Max $P$ \\
Change & Mean & Deviation & Lower & Upper & Value \\
\hline Mandate & -0.227 & 0.024 & -0.302 & -0.152 & 0.011 \\
Ethanol quantity & -0.136 & 0.007 & -0.159 & -0.113 & 0.003 \\
\hline \hline
\end{tabular}

a difference exists, it does not exceed 0.5 percentage points. This indicates that using RIN credits does not translate into significantly smaller impacts on meat markets.

Contrastingly, as shown in Table 3, in the case of grain, feed, and ethanol markets, there is a larger effect when RIN credits are used. Use of RIN credits results in lower prices in all cases, most noticeably for corn and ethanol, compared with no RIN use. With RIN credits, the price of corn and ethanol decreases by $5.58^{17}$ and 14.36 percentage points compared with no RIN use. Because the use of RIN credits decreases ethanol consumption by $8.5 \%$ [ -10.0 , $-7.0]$, there is a discernable decrease in the equilibrium quantities of corn and DG by 1.39 and 1.54 percentage points, respectively, compared with no RIN use. As expected, RIN credits soften ethanol demand from blenders, translating into less demand for corn and, hence, less production of DG.

As expected, use of RIN credits helps to sustain corn demand from meat sectors. With the use of the credits, there is a slightly lower decrease in demand for corn from beef and slight increase in corn demand from pork and poultry sectors compared with the no RIN credits scenario. However, use of RIN credits has no discernable impact on demand for soybean meal from all meat sectors. Although RIN use does not result in a significant change in DG price, there is less demand for DG from all the meat sectors. This is possibly the result of substitution of corn for DG. The use of RINs also dampens the negative impact on export demand for corn (Table 3 ).

\subsection{Estimate on DOM Waiver}

Table 4 presents the simulation results on the level of mandate waiver required to fully offset the impact of the $32 \%$ decrease in rainfall on the equilibrium

17 For approximately 2 billion gallons of RIN use, Tyner, Taheripour, and Hurt (2012) report an approximately 16 percentage point difference in corn prices with and without RINs. Drabik and de Gorter (2012) report an approximately 12 percentage point difference. Our estimate of 5.58 percentage point difference is approximately half of Drabik and de Gorter (2012). Possibly the reduced impact of RIN use in our case is the result of including rainfall elasticity (which is 0.16 for corn and 0.23 for soybean) in our model, which dampens the impact of drought and RIN credits. When rainfall elasticity is made equal to 1 , the difference increases to approximately 10 percentage points. 
corn price. Results indicate that to fully negate the impact of a $32 \%$ decrease in rainfall on the corn price, an approximately $23 \%[-30.2,-15.2]$ mandate waiver (i.e., from 13.6 to 10.47 billion gallons for 2012/2013) is required. This change in policy translates into approximately a $13.63 \%[-15.9,-11.3]$ decrease in ethanol consumption. On average, a $1 \%$ decrease in rainfall leads to approximately $0.26 \%$ increase in corn price, and a $1 \%$ decrease in the mandate results in a $0.38 \%$ decrease in corn price. ${ }^{18}$ Then to fully offset the effect of a $1 \%$ decrease in rainfall, the mandate should be decreased by $0.68 \%$. Given the environmental objectives of the RFS mandate, it may not be feasible for the EPA to fully offset the impact of a drought as severe as the one in 2012. This would require a mandate waiver of 3.12 billion gallons (from 13.6 to 10.47 billion gallons). However, the results do imply that a mandate waiver or use of RIN credits can be an effective tool for mitigating the impact of drought on the corn market when there is a severe drought as in 2012 .

\section{Summary and Conclusions}

To estimate the combined effect of biofuels policy and drought, a stochastic EDM model is developed. This model links the beef, pork, poultry, corn, soybean, soymeal, DG, and ethanol markets. Results suggest that drought has a considerable influence on grain, feed, and meat markets. That influence is exacerbated especially for beef through drought's effect on feed grains and pasture.

Results also suggest that the grain and feed markets are the primary recipients of the supply shock from drought, which is then relayed to the meat markets. Corn prices respond the most to drought with the highest increase among all commodities considered. Among meats, beef is the most affected by drought as it affects supply of feed as well as pasture.

As RIN credits fulfill some of the RFS mandate, they could possibly provide some relief from the effect of drought by helping to lessen the adverse impact on grain markets. However, the impact of RIN usage is limited in effect and is not fully transmitted to the meat markets, particularly beef.

The lower proportionate level of waiver required (approximately 0.68 times the decrease in level of rainfall) to induce a status quo corn price indicates that such a waiver or RIN credits might be a feasible option to mitigate the impact of drought on the corn market. However, it should be underlined that the diminished impact of the corn market may not translate into significant relief for meat markets, limiting the effectiveness of RIN credits or the mandate waiver as an instrument to mitigate the impact of drought for livestock. This may explain at least in part why the EPA did not grant a mandate waiver for 2012.

18 These intermediate calculations are not shown in Table 4. 
The results presented here are indicative rather than definitive because the drought impacts reported are significant over a range of values. Moreover, the confidence interval and associated $P$ values are not generated directly from observational data; the statistical significance in this case may not be directly compatible with the statistical significance from observational data (Davis and Espinoza, 1998). Despite those shortcomings, the model is very useful in general application and in predicting the direction and the magnitude of the range of drought impacts. At the very least, the stochastic nature of the model provides relevant information on the robustness of the results. As with many partial equilibrium models, there is the ceteris paribus assumption with respect to external shocks. Last but not the least, the model has pedagogical value in that it can be used and/or improved on by others for research, extension, and classroom teaching purposes.

\section{Supplementary materials}

To view supplementary material for this article, please visit http://dx.doi.org/ 10.1017/aae.2014.6

\section{References}

Babcock, B. Updated Assessment of the Drought's Impacts on Crop Prices and Biofuel Production. Ames: Center for Agricultural and Rural Development, Iowa State University, CARD Policy Brief 12-PB 8, August 2012.

Bathke, D.J., R.J. Oglesby, C.M. Rowe, and D.A. Wilhite. Understanding and Assessing Climate Change: Implications for Nebraska. Lincoln: University of Nebraska-Lincoln, September 2014.

Brester, G.W., J.M. Marsh, and J.A. Atwood. "Distributional Impacts of Country-of-Origin Labeling in the U.S. Meat Industry." Journal of Agricultural and Resource Economics 29(2004):206-27.

Casella, G., and R. L. Berger. Statistical Inference. 2nd ed. Pacific Grove, CA: Wadsworth Group Thompson Learning, 2002.

Davis, G.C., and M.C. Espinoza. "A Unified Approach to Sensitivity Analysis in Equilibrium Displacement Models." American Journal of Agricultural Economics 80(1998):868-79.

Drabik, D., and H. de Gorter. "Biofuels Policy, Drought and Corn Prices." Biofuels 3(2012):649-51.

Elobeid, A., and S. Tokgoz. "Removal of Distortions in the U.S. Ethanol Market: What Does It Imply for the United States and Brazil?” American Journal of Agricultural Economics 90(2008):918-32.

Elobeid, A., S. Tokgoz, D.J. Hayes, B.A. Babcock, and C.E. Hart. "The Long-Run Impact of Corn-Based Ethanol on the Grain, Oilseed, and Livestock Sectors with Implications for Biotech Crops.” AgBioForum 10(2007):11-18.

Energy Information Administration (EIA). Biofuels Issues and Trends. Washington, DC: U.S. Energy Information Administration, October 2012. 
Hao, N., B. Seong, C. Park, G. Colson, B. Karali, and M. Wetzstein. "Drought, Biofuel, and Livestock." Paper presented at the Agricultural \& Applied Economics Association's 2013 AAEA \& CAES joint annual meeting, Washington, DC, August 4-6, 2013.

Hayes, D., B. Babcock, J. Fabiosa, S. Tokgoz, A. Elobeid, T.-H. Yu, F. Dong, C. Hart, E. Chavez, S. Pan, M. Carriquiry, and J. Dumortier. "Biofuels: Potential Production Capacity, Effects on Grain and Livestock Sectors, and Implications for Food Prices and Consumers." Journal of Agricultural and Applied Economics 41(2009):465-91.

Irwin, S., and D. Good. "Ethanol - Does the RFS Matter?" Farmdoc Daily. UrbanaChampaign: Department of Agricultural and Consumer Economics, University of Illinois, August 2, 2012.

Kruse, J., P. Westhoff, S. Meyer, and W. Thompson. "Economic Impacts of Not Extending Biofuel Subsidies." AgBioForum 10(2007):94-103.

Park, H., and T. R. Fortenbery. "The Effect of Ethanol Production on the U.S. National Corn Price." Paper presented at the NCCC-134 Conference Proceedings on Applied Commodity Price Analysis, Forecasting, and Market Risk Management, Chicago, April 16-17, 2007.

Paulson, N. "An Update on the 2012 RIN Carryover Controversy." Farmdoc Daily. UrbanaChampaign: Department of Agricultural and Consumer Economics, University of Illinois, April 12, 2013.

—. "RIN Stock Update: Implications of the 2012 Drought." Farmdoc Daily. UrbanaChampaign: Department of Agricultural and Consumer Economics, University of Illinois, December 14, 2012.

Peters, M., A. Somwaru, J. Hansen, R. Seeley, and S. Dirkse. “Modeling Biofuels Expansion in a Changing Global Environment." Paper presented at the International Association of Agricultural Economics Conference, Beijing, August 16-22, 2009.

Rask, K.N. "Clean Air and Renewable Fuels: The Market for Fuel Ethanol in the U.S. from 1984 to 1993." Energy Economics 20(1998):325-45.

Richardson, J.W., K.D. Schumann, and P.A. Feldman. SIMETAR: Simulation \& Econometrics to Analyze Risk. College Station, TX: Simetar, 2008.

RTI International. GIPSA Livestock and Meat Marketing Study, Volume 3: Fed Cattle and Beef Industries. Research Triangle Park, NC: RTI International, January 2007.

Taheripour, F., T.W. Hertel, and W.E. Tyner. "Implications of the Biofuels Boom for the Global Livestock Industry: A Computable General Equilibrium Analysis.” Agricultural Economics 42(2011):325-42.

Thompson, W., J. Whistace, P. Westhoff, and J. Binfield. Renewable Fuel Standard Waiver Options during the Drought of 2012. Columbus: Food and Agricultural Policy Institute, University of Missouri, FAPRI-MU Report \#11-12, October 2012.

Tokgoz, S., A. Elobeid, J. Fabiosa, D.J. Hayes, B.A. Babcock, T. Yu, F. Dong, and C.E. Hart. "Bottlenecks, Drought, and Oil Price Spikes: Impact on U.S. Ethanol and Agricultural Sectors." Review of Agricultural Economics 30(2008):604-22.

Tyner, W.E., F. Taheripour, and C. Hurt. Potential Impacts of a Partial Waiver of the Ethanol Blending Rules. West Lafayette: Department of Agricultural Economics, Purdue University, August 2012.

U.S. Environmental Protection Agency (EPA). EPA Decision to Deny Requests for Waiver of the Renewable Fuel Standard. Washington, DC: U.S. Environmental Protection Agency, EPA-420-F-12-075, November 2012.

Weng, T. "Welfare Effects of the Horizontal Consolidation in the Broiler Industry." Unpublished manuscript, Department of Agricultural and Resource Economics, North Carolina State University, March 2012. 
Westcott, P.C., and M. Jewison. Weather Effects on Expected Corn and Soybean Yields. Washington, DC: U.S. Department of Agriculture, Economic Research Service, FDS13g-01, July 2013.

Wiles, L.J., G. Dunn, J. Printz, B. Patton, and A. Nyren. "Spring Precipitation as a Predictor for Peak Standing Crop of Mixed-Grass Prairie.” Rangeland Ecology \& Management 64(2011): 215-22.

Wise, T.A., and S.E. Trist. "Buyer Power in U.S. Hog Markets: A Critical Review of the Literature.” Working paper no. 10-04, Global Development and Environment Institute, Tufts University, Boston, 2010.

Wohlgenant, M.K. "Consumer Demand and Welfare in Equilibrium Displacement Models." The Oxford Handbook of the Economics of Food Consumption and Policy. J. L. Lusk, J. Roosen, and J. Shogren, eds. Oxford: Oxford University Press, 2011.

\section{Appendix}

\section{Log Differential Equations of the Structural Models}

\section{Beef market:}

$$
\begin{aligned}
& d \ln Q_{b}^{r d}-\eta_{b}^{r} d \ln P_{b}^{r}-\eta_{b p}^{r} d \ln P_{p}^{r}-\eta_{b k}^{r} d \ln P_{k}^{r}=0 \\
& d \ln Q_{b}^{r s}-\varepsilon_{b}^{r} d \ln P_{b}^{r}-\tau_{b}^{r w} d \ln Q_{b}^{w}=0 \\
& d \ln Q_{b}^{w d}-\eta_{b}^{w} d \ln P_{b}^{w}-\tau_{b}^{w r} d \ln Q_{b}^{r}=0 \\
& d \ln Q_{b}^{w s}-\varepsilon_{b}^{w} d \ln P_{b}^{w}-\tau_{b}^{w s} d \ln Q_{b}^{s}=0 \\
& d \ln Q_{b}^{s d}-\eta_{b}^{s} d \ln P_{b}^{s}-\tau_{b}^{s w} d \ln Q_{b}^{w}=0 \\
& d \ln Q_{b}^{s s}-\varepsilon_{b}^{s} d \ln P_{b}^{s}-\tau_{b}^{s f} d \ln Q_{b}^{f}-\varepsilon_{c o}^{b} d \ln P_{c o}-\varepsilon_{s y m}^{b} d \ln P_{s y m} \\
& \quad-\varepsilon_{D G}^{b} d \ln P_{D G}=0 \\
& \ln Q_{b}^{f d}-\eta_{b}^{f} d \ln P_{b}^{f}-\tau_{b}^{f s} d \ln Q_{b}^{s}=0 \\
& d \ln Q_{b}^{f s}-\varepsilon_{b}^{f} d \ln P_{b}^{f}=\varepsilon_{b}^{g} d \ln W_{g}^{19,20}
\end{aligned}
$$

Pork market:

$$
d \ln Q_{p}^{r d}-\eta_{p}^{r} d \ln P_{p}^{r}-\eta_{p b}^{r} d \ln P_{b}^{r}-\eta_{p k}^{r} d \ln P_{k}^{r}=0
$$

19 The elasticity of cattle supply with respect to pasture yield $\left(W_{g}\right)$ is not available in the literature. Consultation with a range specialist revealed that during drought the general tendency is to overgraze pasture to maintain production. This implies that the elasticity of cattle supply with respect to pasture yield is inelastic. The irresponsiveness is also supported by the fact that pasture is not the only source of feed during drought; hay from previous years or corn stalks can be also be used to supplement the pasture supply making the response to pasture decline relatively inelastic. Because there is no estimate in the literature, we assume $\varepsilon_{b}^{g}=0.25$.

20 To find the relationship between pasture yield and rainfall, the regression estimates from Wiles et al. (2011) are rescaled and converted into elasticity at mean estimates using the information provided in the article. The elasticity estimate used in this article is the average of the estimate for North Dakota, Montana, and Wyoming provided in Wiles et al. (2011). 


$$
\begin{aligned}
& d \ln Q_{p}^{r s}-\varepsilon_{p}^{r} d \ln P_{p}^{r}-\tau_{p}^{r w} d \ln Q_{p}^{w}=0 \\
& d \ln Q_{p}^{w d}-\eta_{p}^{w} d \ln P_{p}^{w}-\tau_{p}^{w r} d \ln Q_{p}^{r}=0 \\
& d \ln Q_{p}^{w s}-\varepsilon_{p}^{w} d \ln P_{p}^{w}-\tau_{p}^{w f} d \ln Q_{p}^{f}=0 \\
& d \ln Q_{p}^{f d}-\eta_{p}^{f} d \ln P_{p}^{f}-\tau_{p}^{f w} d \ln Q_{p}^{w}=0 \\
& d \ln Q_{p}^{f s}-\varepsilon_{p}^{f} d \ln P_{p}^{f}-\varepsilon_{p c o}^{f} d \ln P_{c o}-\varepsilon_{p s y m}^{f} d \ln P_{s y m}-\varepsilon_{p D G}^{f} d \ln P_{D G}=0
\end{aligned}
$$

Poultry market:

$$
\begin{aligned}
& d \ln Q_{k}^{r d}-\eta_{k}^{r} d \ln P_{k}^{r}-\eta_{k b}^{r} d \ln P_{b}^{r}-\eta_{k p}^{r} d \ln P_{p}^{r}=0 \\
& d \ln Q_{k}^{r s}-\varepsilon_{k}^{r} d \ln P_{k}^{r}-\tau_{k}^{r w} d \ln Q_{k}^{w}=0 \\
& d \ln Q_{k}^{w d}-\eta_{k}^{w} d \ln P_{k}^{w}-\tau_{k}^{w r} d \ln Q_{k}^{r}=0 \\
& d \ln Q_{k}^{w s}-\varepsilon_{k}^{w} d \ln P_{k}^{w}-\varepsilon_{p c o}^{w} d \ln P_{c o}-\varepsilon_{p s y m}^{w} d \ln P_{s y m}-\varepsilon_{p D G}^{w} d \ln P_{D G}=0
\end{aligned}
$$

Corn market:

$$
\begin{aligned}
& d \ln Q_{c o}^{b}-\eta_{c o}^{b} d \ln P_{c o}-\tau^{c o, s} d \ln Q_{b}^{s}-\eta_{c o, s y m}^{b} d \ln P_{s y m}-\eta_{c o, D G}^{b} d \ln P_{D G}=0 \\
& d \ln Q_{c o}^{p}-\eta_{c o}^{p} d \ln P_{c o}-\tau^{c o, p} d \ln Q_{p}^{f}-\eta_{c o, s y m}^{p} d \ln P_{s y m}-\eta_{c o, D G}^{p} d \ln P_{D G}=0 \\
& d \ln Q_{c o}^{k}-\eta_{c o}^{k} d \ln P_{c o}-\tau^{c o, k} d \ln Q_{k}^{w}-\eta_{c o, s y m}^{k} d \ln P_{s y m}-\eta_{c o, D G}^{k} d \ln P_{D G}=0 \\
& d \ln Q_{c o}^{e}-\eta_{c o}^{e} d \ln P_{c o}-\tau^{c o, e} d \ln Q_{e}=0 \\
& d \ln Q_{c o}^{x}-\eta_{c o}^{x} d \ln P_{c o}=0 \\
& d \ln Q_{c o}^{d}-S_{b}^{c o} d \ln Q_{c o}^{b}-S_{p}^{c o} d \ln Q_{c o}^{p}-S_{k}^{c o} d \ln Q_{c o}^{k}-S_{e}^{c o} d \ln Q_{c o}^{e} \\
& \quad-S_{x}^{c o} d \ln Q_{c o}^{x}=0 \\
& d \ln Q_{c o}^{s}-\varepsilon_{c o} d \ln P_{c o}=\varepsilon_{c o}^{R} d \ln R^{21}
\end{aligned}
$$

Soybean and soybean meal market:

$$
\begin{aligned}
& d \ln Q_{s y m}^{b}-\eta_{s y m}^{b} d \ln P_{s y m}-\tau^{s y m, s} d \ln Q_{b}^{s}-\eta_{s y m, c o}^{b} d \ln P_{c o}-\eta_{s y m, D G}^{b} d \ln P_{D G}=0 \\
& d \ln Q_{s y m}^{p}-\eta_{s y m}^{p} d \ln P_{s y m}-\tau^{s y m, p} d \ln Q_{p}^{f}-\eta_{s y m, c o}^{p} d \ln P_{c o}-\eta_{D G, s y m}^{p} d \ln P_{D G}=0
\end{aligned}
$$

$21 \varepsilon_{c o}^{R}=0.16$. The elasticities of corn and soybean yield with respect to rainfall are calculated using precipitation slope coefficients and 2012 precipitation and corn yield values reported by Westcott and Jewison (2013). 


$$
\begin{aligned}
& d \ln Q_{s y m}^{k}-\eta_{s y m}^{k} d \ln P_{s y m}-\tau^{s y m, k} d \ln Q_{k}^{w}-\eta_{s y m, c o}^{k} d \ln P_{c o}-\eta_{s y m, D G}^{k} d \ln P_{D G}=0 \\
& d \ln Q_{s y m}^{x}-\eta_{s y m}^{x} d \ln P_{s y m}=0 \\
& d \ln Q_{s y m}^{d}-S_{b}^{s y m} d \ln Q_{s y m}^{b}-S_{p}^{s y m} d \ln Q_{s y m}^{p}-S_{k}^{s y m} d \ln Q_{s y m}^{k}-S_{x}^{s y m} d \ln Q_{s y m}^{x}=0 \\
& d \ln Q_{s y m}^{s}-\varepsilon_{s y m} d \ln P_{s y m}-\tau_{s y m}^{b} d \ln Q_{s y}=0 \\
& d \ln Q_{s y}^{d}-\eta_{s y} \ln P_{s y}-\eta_{s y, s y m}^{s y} d \ln P_{s y m}=0 \\
& d \ln Q_{s y}^{x}-\eta_{s y}^{x} d \ln P_{s y}=0 \\
& d \ln Q_{s y}^{\prime} S^{s y} d \ln Q_{s y}^{d}-S_{x}^{s y} d \ln Q_{s y}^{x}=0 \\
& d \ln Q_{s y}^{s}-\varepsilon_{s y} d \ln P_{s y}=\varepsilon_{s y}^{R} d \ln R^{22}
\end{aligned}
$$

Distillers' grain market:

$$
\begin{aligned}
& d \ln Q_{D G}^{b}-\eta_{D G}^{b} d \ln P_{D G}-\tau^{D G, s} d \ln Q_{b}^{s}-\eta_{D G, c o}^{b} d \ln P_{c o}-\eta_{D G, s y m}^{b} d \ln P_{s y m}=0 \\
& d \ln Q_{D G}^{p}-\eta_{D G}^{p} d \ln P_{D G}-\tau^{D G, h} d \ln Q_{p}^{f}-\eta_{D G, c o}^{p} d \ln P_{c o}-\eta_{D G, s y m}^{p} d \ln P_{s y m}=0 \\
& d \ln Q_{D G}^{k}-\eta_{D G}^{k} d \ln P_{D G}-\tau^{D G, k} d \ln Q_{k}^{w}-\eta_{D G, c o}^{k} d \ln P_{c o}-\eta_{D G, s y m}^{k} d \ln P_{s y m}=0 \\
& d \ln Q_{D G}^{x}-\eta_{D G}^{x} d \ln P_{D G}=0 \\
& d \ln Q_{D G}^{d}-S_{b}^{D G} d \ln Q_{D G}^{b}-S_{p}^{D G} d \ln Q_{D G}^{h}-S_{k}^{D G} d \ln Q_{D G}^{k}-S_{x}^{D G} d \ln Q_{D G}^{x}=0 \\
& d \ln Q_{D G}^{s}-0.18 d \ln Q_{c o}^{e}=0
\end{aligned}
$$

Ethanol market:

$$
\begin{aligned}
& d \ln Q_{e}^{d}-\eta_{e} d \ln P_{e}=\eta_{e}^{m} d \ln M^{23} \\
& d \ln Q_{e}^{s}-\varepsilon_{e} d \ln P_{e}-\varepsilon_{e, c o} \ln P_{c o}=0
\end{aligned}
$$

$22 \varepsilon_{s y}^{R}=0.23$ (Wescott and Jewison, 2013).

$23 \eta_{e}^{m}=1$. The assumption here is that the level of ethanol consumption is equal to the level of the mandate when the mandate does not exceed the blend wall, and any change in the mandate shifts the ethanol demand curve by the amount of mandate change. This means that the proportionate change in ethanol consumption is equal to the proportionate change in the mandate. 